\title{
PENGARUH KEPEMIMPINAN TRANSFORMASIONAL DAN LINGKUNGAN KERJA TERHADAP TURNOVER INTENTION DENGAN KOMITMEN ORGANISASIONAL SEBAGAI VARIABEL MEDIASI PADA KARYAWAN PT. BORNEO ICON PROPERTI
}

\author{
Dini Dwi Damayanti a \\ *abc Magister Manajemen, Fakultas Ekonomi dan Bisnis, Universitas Tanjungpura, \\ Pontianak \\ *Email : dinidwidamayanti@gmail.com \\ (Diterima November 2019; Disetujui Juni 2020; Dipublikasikan Juli 2020)
}

\begin{abstract}
Abstrak
Salah satu faktor yang dapat mempengaruhi turnover karyawan adalah peran pemimpin yang memiliki gaya kepemimpinan transformasional dan lingkungan kerja yang mendukung sehingga dapat mendorong sumber daya manusia di perusahaan agar terus produktif serta dapat menumbuhkan komitmen organisasional karyawannya. Penelitian ini merupakan penelitian penjelasan (Explanatory Research) dengan jenis penelitian deskriptif kuantitatif. Penelitian survei menggunakan kuesioner melalui google form yang disebarkan kepada karyawan PT. Borneo Icon Properti dengan jumlah responden 45 orang. Metode analisis yang digunakan pada hipotesis adalah analisis jalur (path analysis).

Hasil Penelitian ini menunjukkan bahwa kepemimpinan transformasional berpengaruh secara signifikan terhadap komitmen organisasional, lingkungan kerja berpengaruh signifikan terhadap komitmen organisasional, gaya kepemimpinan transformasional tidak berpengaruh secara signifikan terhadap turnover intention dan lingkungan kerja berpengaruh negatif dan tidak signifikan terhadap turnover intention, dan komitmen organisasional berpengaruh secara negatif dan tidak signifikan terhadap turnover intention. Serta dari hasil analisis jalur variabel komitmen organisasional tidak memediasi baik kepemimpinan transformasional dan lingkungan kerja terhadap turnover intention pada karyawan PT. Borneo Icon
\end{abstract}

Kata Kunci : Gaya Kepemimpinan Transformasional, Lingkungan Kerja, Komitmen Organisasional, Turnover Intention.

\section{LATAR BELAKANG}

Dampak pesatnya perkembangan dari era globalisasi ini, peran sumber daya manusia menjadi sorotan yang sangat penting bagi setiap organisasi agar dapat mempertahankan eksistensinya dalam menghadapi persaingan. Termasuklah menjadi tantangan bagi perusahaan-perusahaan yang bergerak pada sektor pembangun perumahan atau biasa disebut dengan developer properti. Usaha properti sangatlah memiliki banyak manfaat bagi masyarakat luas dimana sebagai pelaku usaha tersebut bermanfaat dalam membantu masyarakat atau dapat dikatakan konsultan yang berperan memberikan informasi-informasi serta pengetahuan bagi masyarakat yang ingin memiliki rumah. Saat ini khususnya di Indonesia pembangunan 
properti terus meningkat tiap tahunnya yang menandakan perbaikan ekonomi yang signifikan ke arah masa depan yang lebih baik (Rafitas, 2005).

Di Kalimantan Barat, usaha properti semakin diminati oleh banyak pelaku usaha dikarenakan mendatangkan profit yang menjanjikan, karena tiap tahunnya banyak perusahaan properti yang ingin semakin dikenal luas oleh masyarakat dan berkompetisi meluncurkan produk-produk perumahan dengan promo atau program-program yang menarik agar dipilih oleh masyarakat. Borneo Icon Properti merupakan pemain baru yang terjun dalam usaha properti di Kalimantan Barat, yang telah berdiri sejak 2016 silam. Tingkat turnover yang sangat tinggi akan menjadikan biaya yang cukup besar bagi perusahaan. Begitu pula yang terjadi di perusahaan Borneo Icon Properti pada tahun 2019 persentase turnover karyawan sebesar 15\% dari total karyawan saat ini sebanyak 45 karyawan. Berikut merupakan data turnover karyawan PT. Borneo Icon Properti selama setahun terakhir.

\begin{tabular}{|c|c|c|c|c|}
\hline No & Bulan & $\begin{array}{c}\text { Jumlah } \\
\text { Karyawan }\end{array}$ & Masuk & Mengundurkan diri \\
\hline 1 & Januari & 40 & 3 & 2 \\
\hline 2 & Februari & 41 & 5 & 3 \\
\hline 3 & Maret & 43 & 2 & 1 \\
\hline 4 & April & 42 & 6 & 3 \\
\hline 5 & Mei & 45 & 2 & 1 \\
\hline 6 & Juni & 44 & 2 & 2 \\
\hline 7 & Juli & 45 & 1 & 2 \\
\hline 8 & Agustus & 44 & 3 & 3 \\
\hline 9 & September & 45 & 4 & 4 \\
\hline 10 & Oktober & 46 & 5 & 2 \\
\hline 11 & November & 46 & 2 & 3 \\
\hline 12 & Desember & 45 & 2 & $\mathbf{4 5}$ \\
\hline \multicolumn{5}{|c|}{ Total Karyawan di tahun 2019 } \\
\hline
\end{tabular}

Sumber : PT. Borneo Icon Properti, 2019

Berdasarkan data tersebut mencerminkan sering terjadi keluar masuknya karyawan. Ciri yang muncul dari perilaku karyawan yaitu adanya tindakan mulai malas dalam melakukan pekerjaan seperti menunda pekerjaan, datang terlambat, dan absensi yang meningkat sehingga tugas yang diberikan menjadi menumpuk serta tidak diselesaikan tepat waktu. 
Pengaruh Kepemimpinan Transformasional dan Lingkungan Kerja terhadap Turnover Intention dengan Komitmen Organisasional sebagai Variabel Mediasi pada Karyawan

PT. Borneo Icon Properti

Dini Dwi Damayanti a

Turnover intention pada perusahaan juga dapat disebabkan pemimpin yang kurang memperhatikan kebutuhan karyawannya dalam bekerja, kurang memperhatikan keluhan-keluhan karyawan, serta kurang memahami kebutuhan karyawan akan lingkungan kerja yang nyaman sebagaimana mestinya. Hal ini lambat laun berpengaruh terhadap komitmen karyawan dan terjadinya turnover intention. Oleh karenanya tidak heran pada perusahaan swasta seperti ini sering terjadi keluar masuknya karyawan. Tingkat turnover yang tergolong tinggi umumnya turnover dinyatakan dalam satu tahun tidak boleh lebih dari 10\%. (Ridlo, 2012). Denvir \& McMahon dalam Faldeta et al (2013) mendefinisikan turnover sebagai pergerakan orang baik ke dalam maupun keluar dari pekerjaan dalam sebuah organisasi.

Gaya pemimpin dalam mengarahkan bawahannya dapat mempengaruhi bertahannya atau tidaknya karyawan yang ada di dalam organisasi. Salah satu gaya kepemimpinan yang dapat tercerminkan disebuah oranisasi yaitu gaya kepemimpinan transformasional. Di dalam sebuah jurnal Clinebell et al (2013) dengan judul "Impact of Leadership Style On Employee

Organizational Commitment" manyatakan bahwa gaya kepemimpinan transformasional secara positif berpengaruh terhadap komitmen organisasi. Menurut Griffeth \& Hom (2000) mengemukakan bahwa ada beberapa penelitian yang mengidentifikasi faktor-faktor yang mempengaruhi keinginan karyawan untuk berhenti bekerja salah satunya adalah gaya kepemimpinan.

Turnover intention memiliki hubungan yang sangat erat dengan turnover, sehingga dengan memahami faktor yang mempengaruhi turnover intention adalah cara efektif untuk mengurangi actual turnover. Hartog \& Ophem (2004) dalam Wei Su (2014) menguraikan bahwa turnover intention merefleksikan kemungkinan seseorang akan merubah atau berpindah pekerjaan dalam periode waktu tertentu. Salah satu prediktor yang digunakan untuk mengukur turnover intention adalah melalui komitmen organisasional.

Selain itu lingkungan kerja juga merupakan faktor penting yang menentukan keberhasilan suatu organisasi. lingkungan kerja non fisik adalah semua keadaan yang terjadi yang berkaitan dengan hubungan kerja, baik dengan atasan maupun dengan sesama rekan kerja, ataupun dengan bawahan (Sedarmayati, 2009). Menurut Negirin \& Shay (2004) menyatakan 
Pengaruh Kepemimpinan Transformasional dan Lingkungan Kerja terhadap Turnover Intention dengan Komitmen Organisasional sebagai Variabel Mediasi pada Karyawan

PT. Borneo Icon Properti

Dini Dwi Damayanti a

bahwa kondisi kerja yang lemah dan tidak menguntungkan muncul sebagai alasan utama untuk niat keluar yang tinggi di antara karyawan-karyawan.

\section{LANDASAN TEORI}

\section{Kepemimpinan Transformasional}

Menurut Robbins \& Judges (2010) pemimpin transformasional mencurahkan perhatian pada hal-hal dan kebutuhan pengembangan dari masing-masing pengikut, pemimpin transformasional mengubah kesadaran para pengikut akan persoalan-persoalan dengan membantu mereka memandang masalah lama dengan cara-cara baru, dan mereka mampu menggairahkan, membangkitkan, dan mengilhami para pengikut untuk mengeluarkan upaya ekstra demi mencapai sasaran kelompok. Kepemimpinan transformasional mengacu pada proses di mana para pemimpin menumbuhkan komitmen pengikut dan mendorong mereka untuk mengatasi kepentingan diri mereka demi tujuan organisasi, memperoleh komitmen mereka dan menghasilkan perubahan besar dan kinerja tinggi (Rego \& Cunha, 2008). Menurut Robbins \& Judge (2010) terdapat empat komponen kepemimpinan transformasional , yaitu :
a. Pengaruh Ideal (Idealized Influence)
b. Motivasi Inspirasional (Inspirational Motivation)
c. Konsiderasi Individual (Individualized Consideration)
d. Stimulasi Intelektual (Intelectual Simulation)

\section{Lingkungan Kerja}

Lingkungan kerja merupakan faktor penting yang dapat mempengaruhi hasil kerja para individu yang ada di dalam organisasi. Lingkungan kerja mengacu pada suasana organisasi tempat karyawan melakukan pekerjaannya (Danish, et al 2013). Lingkungan kerja adalah segala sesuatu yang ada di sekitar para pekerja dan yang dapat mempengaruhi dirinya dalam menjalankan tugas-tugas yang dibebankan. Lingkungan fisik adalah alat yang dapat dimanfaatkan secara baik untuk meningkatkan hasil bisnis (McGuire \& McLaren, 2009). Sementara Sedarmayanti, (2001) membagi lingkungan kerja menjadi dua bagian, yaitu : (a) lingkungan kerja fisik dan (b) Lingkungan kerja non fisik adalah semua keaadan berbentuk fisik yang 
Pengaruh Kepemimpinan Transformasional dan Lingkungan Kerja terhadap Turnover Intention dengan Komitmen Organisasional sebagai Variabel Mediasi pada Karyawan PT. Borneo Icon Properti Dini Dwi Damayanti a

terdapat disekitar tempat kerja yang dapat mempengaruhi karyawan baik secara langsung maupun secara tidak langsung. Lingkungan kerja non fisik adalah semua keadaan yang terjadi yang berkaitan dengan hubungan kerja, baik hubungan dengan atasan maupun hubungan sesama rekan kerja, ataupun hubungan dengan bawahan Indikator lingkungan kerja yang meliputi : prosedur kerja, standar kerja, kejelasan tugas, sistem penghargaan, dan hubungan antar karyawan. (sedarmayanti,2001).

\section{Komitmen Organisasional}

Komitmen organisasional telah didefinisikan sebelumnya sebagai sikap psikologis yang melekatkan karyawan ke organisasi dengan cara yang mengurangi niat berpindahnya (Allen \& Meyer, 1990). Menurut Mathis \& Jackson dalam Satwari et al (2014) komitmen organisasional adalah tingkat sampai dimana karyawan yakin dan menerima tujuan organisasional serta berkeinginan untuk tinggal bersama organisasi. Komitmen terhadap perusahaan meliputi sikap menyukai perusahaan dan kesediaan untuk mengusahakan tingkat upaya yang tinggi bagi kepentingan perusahaan demi pencapaian tujuan. Menurut Allen \& Meyer (1990) terdapat tiga dimensi komitmen organisasional yaitu komitmen afektif, komitmen normatif, dan komitmen berkelanjutan.

\section{Turnover Intention}

Intention merupakan niat atau keinginan dari seseorang untuk melakukan sesuatu hal. Intensi menurut Ajzen \& Fishbein (1980) adalah komponen dalam diri individu yang mengacu pada keinginan untuk melakukan tingkah laku tertentu sedangkan Turnover adalah keluar masuknya tenaga kerja dalam suatu perusahaan dalam kurun waktu tertentu (Flippo, 2002). Tentu di dalam sebuah organisasi menjadi sebuah fenomena pergantian atau terjadi keluar masuknya karyawan sehingga hal ini menjadi penting untuk lebih diperhatikan. Indikasi turnover intention yang muncul di sebuah organisasi meliputi : absensi yang meningkat, mulai tidak bersemangat dalam bekerja, sering melakukan pelanggaran tata tertib organisasi, dan dan tidak serius dalam melaksanakan tanggung jawab. Çınar (2015) mendefinisikan turnover intention sebagai keinginan karyawan untuk meninggalkan perannya saat ini karena ada tersedia peluang yang lebih baik. Peneliti lainpun sependapat bahwa turnover intention adalah proses kognitif yang mencakup serangkaian keputusan mental sebelum karyawan berhenti dari pekerjaannya pada suatu organisasi Dwivedi (2015). 
Pengaruh Kepemimpinan Transformasional dan Lingkungan Kerja terhadap Turnover Intention dengan Komitmen Organisasional sebagai Variabel Mediasi pada Karyawan

PT. Borneo Icon Properti

Dini Dwi Damayanti a

\section{KERANGKA KONSEPTUAL}

Berikut merupakan kerangka konseptual yang bersumber pada kajian empiris penelitian sebelumnya.

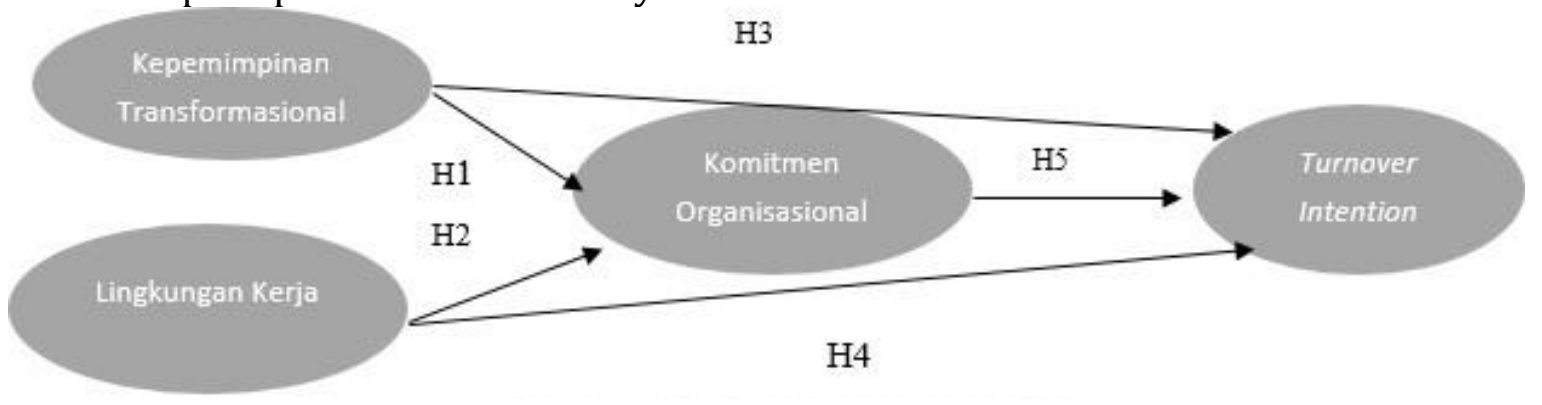

\section{Kerangka Konseptual \\ HIPOTESIS PENELITIAN \\ Kajian Empiris}

Berdasarkan kerangka pemikiran dan yang ada dan permasalahan yang telah diuraikan, maka hipotesis penelitian ini adalah sebagai berikut :

H1 :Kepemimpinan transformasional berpengaruh signifikan positif terhadap komitmen organisasional karyawan PT. Borneo Icon Properti

H2 :Lingkungan kerja berpengaruh signifikan positif terhadap komitmen organisasional karyawan PT. Borneo Icon Properti

H3 :Kepemimpinan transformasional berpengaruh signifikan negatif terhadap turnover intention karyawan PT. Borneo Icon Properti

H4 :Lingkungan kerja berpengaruh signifikan negatif terhadap turnover intention karyawan PT. Borneo Icon Properti

H5 :Komitmen organisasional berpengaruh signifikan negatif terhadap turnover intention

karyawan PT. Borneo Icon Properti

H6 :Kepemimpinan transformasional berpengaruh secara negatif dan signifikan terhadap

turnover intention melalui komitmen organisasional karyawan PT. Borneo Icon Prope Properti 
Pengaruh Kepemimpinan Transformasional dan Lingkungan Kerja terhadap Turnover Intention dengan Komitmen Organisasional sebagai Variabel Mediasi pada Karyawan

PT. Borneo Icon Properti

Dini Dwi Damayanti a

H7 :Lingkungan kerja berpengaruh secara negatif dan signifikan terhadap turnover intention

melalui komitmen organisasional karyawan PT. Borneo Icon Properti

\section{METODE PENELITIAN}

\section{Bentuk Penelitian}

Bentuk penelitian yang digunakan dalam penelitian ini adalah penelitian penjelasan (Explanatory Research), dimana menurut sugiono (2012), "Explanatory Research digunakan untuk menjelaskan hubungan kausal antara variabel-variabel melalui penguji hipotesa". Jenis penelitian ini adalah deskriptif kuantitatif. Pengumpulkan data melalui metode penelitian survey terhadap karyawan. Alat untuk mengumpulkan data yang digunakan adalah observasi dan penyebaran kuesioner pada objek penelitian. Pada akhirnya data kuantitatif dalam penelitian ini adalah karyawan pada PT. Borneo Icon Properti.

\section{Tempat dan Waktu Penelitian}

Penelitian ini dilakukan di PT. Borneo Icon Properti yang berlokasi di Jalan Tani Makmur No.2 Pontianak.

\section{Jenis dan Sumber Data}

Metode pengumpulan data akan menjelaskan jenis data dan pengambilan sampel yang digunakan dalam penelitian ini, jenis data yang digunakan dalam penelitian ini adalah data kualitatif (data yang berbentuk kata-kata) dan data kuantitatif (data yang berbentuk angka atau bilangan). Sedangkan sumber data yang digunakan dalam penelitian ini adalah:

1. Data primer yaitu teknik yang dapat digunakan peneliti untuk mengumpulkan data primer antara lain observasi, wawancara dan penyebaran kuesioner secara langsung maupun online.

2. Data Sekunder adalah data yang diperoleh atau dikumpulkan peneliti dari berbagai sumber yang telah ada. Data sekunder dapat diperoleh dari berbagai sumber seperti buku dan jurnal mengenai sumber daya manusia dan statistik, gaya kepemimpinan transformasional, lingkungan kerja, komitmen organisasional dan turnover intention pegawai PT. Borneo Icon Properti. 
Pengaruh Kepemimpinan Transformasional dan Lingkungan Kerja terhadap Turnover Intention dengan Komitmen Organisasional sebagai Variabel Mediasi pada Karyawan

PT. Borneo Icon Properti

Dini Dwi Damayanti a

\section{Populasi}

Adapun populasi yang akan diteliti adalah seluruh karyawan PT. Borneo Icon Properti yang berjumlah 45 orang karyawan.

\section{Sampel}

Menurut Sugiono (2017), "Sampel adalah bagian dari jumlah dan karakteristik yang dimiliki oleh populasi”. Dalam penelitian ini menggunakan sampling jenuh / sensus karena sampel yang diteliti merupakan keseluruhan dari populasi yang ada atau disebut dengan sensus (sampel jenuh). Sampel diambil di PT. Borneo Icon Properti memiliki jumlah pegawai sebanyak 45 karyawan

\section{Skala Pengukuran Variabel}

Menurut Sugiyono (2012) skala likert digunakan untuk mengukur sikap, pendapat dan presepsi seseorang atau kelompok orang tentang fenomena sosial. Untuk kep erluan analisis kuantitatif penelitian maka peneliti memberikan lima alternatif jawaban untuk dijawab oleh para responden dengan menggunakan skor 1 sampai dengan 5 dapat dilihat dari Tabel berikut:

\section{Instrumen Skala Likert}

\begin{tabular}{|c|l|c|}
\hline No & \multicolumn{1}{|c|}{ Jawaban } & Skor \\
\hline 1 & Sangat Setuju (SS) & 5 \\
\hline 2 & Setuju (S) & 4 \\
\hline 3 & Kurang Setuju (KS) & 3 \\
\hline 4 & Tidak Setuju (TS) & 2 \\
\hline 5 & Sangat Tidak Setuju (STS) & 1 \\
\hline
\end{tabular}

Sumber : Sugiyono (2012)

Teknik Analisis Data

1. Uji instrumen terdiri dari uji validitas dan reliabilitas.

2. Uji asumsi klasik terdiri dari normalitas dan linearitas.

3. Uji analisis jalur, uji determinasi total (R2), dan uji parsial (t).

4. Sobel Test.

HASIL PENELITIAN DAN PEMBAHASAN

\section{Uji Normalitas}


Pengaruh Kepemimpinan Transformasional dan Lingkungan Kerja terhadap Turnover Intention dengan Komitmen Organisasional sebagai Variabel Mediasi pada Karyawan

PT. Borneo Icon Properti

Dini Dwi Damayanti a

Uji normalitas data ini diperlukan karena hasil uji statistik akan diinterpretasikan kedalam parameter dalam populasi. Dasar keputusan jika nilai sig > 0,05 maka data residual terdistribusikan normal. Berikut adalah Tabel uji statistik:

\section{Uji Normalitas Persamaan 1}

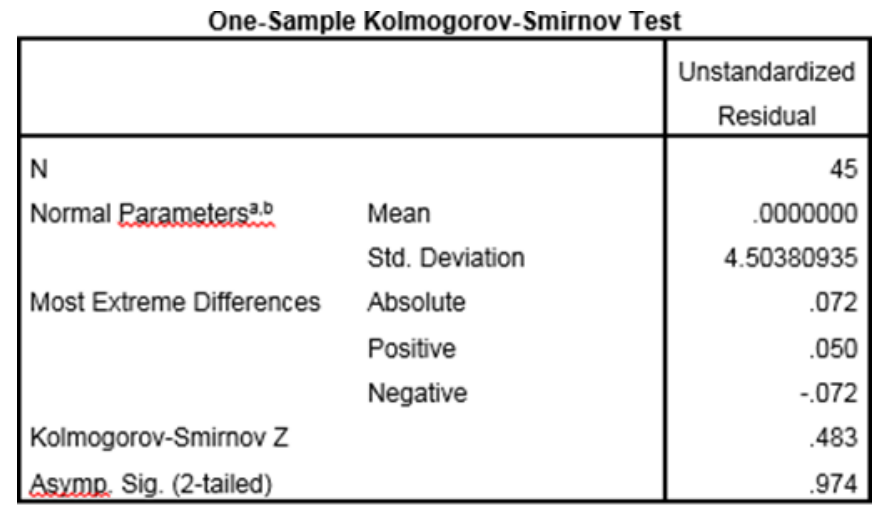

a. Test distribution is Normal.

b. Calculated from data.

Uji Normalitas Persamaan 2

\begin{tabular}{|ll|r|}
\hline \multicolumn{2}{|c|}{ One-Sample Kolmogorov-Smirnov Test } \\
\hline $\mathrm{N}$ & $\begin{array}{c}\text { Unstandardized } \\
\text { Residual }\end{array}$ \\
Normal Parameters ${ }^{\mathrm{a} . \mathrm{b}}$ & Mean & 45 \\
& Std. Deviation & .0000000 \\
Most Extreme Differences & Absolute & 8.20002498 \\
& Positive & .160 \\
& Negative & .160 \\
Kolmogorov-Smirnov Z & & -.113 \\
Asymo. Sig. (2-tailed) & & 1.071 \\
\hline
\end{tabular}

a. Test distribution is Normal.

b. Calculated from data.

Sumber : Data olahan, 2020

Berdasarkan Tabel 4.19 dan 4.20 dapat dilihat nilai signifikan kedua residu adalah 0,974 dan 0,201 yang keduanya memiliki nilai $>0,05$. Oleh karena itu, dapat disimpulkan data pada penelitian ini berdistribusi normal.

\section{Uji Linearitas}

Uji linearitas bertujuan untuk mengetahui apakah dua variabel mempunyai hubungan yang linear atau tidak dilihat dari nilai signifikansi yang *corresponding authors e-mail : dinidwidamayanti@gmail.com Online ISSN: 2721-4230 | Print ISSN: 2721-4281 
Pengaruh Kepemimpinan Transformasional dan Lingkungan Kerja terhadap Turnover Intention dengan Komitmen Organisasional sebagai Variabel Mediasi pada Karyawan

PT. Borneo Icon Properti

Dini Dwi Damayanti a

dihasilkan melalui pengujian test for linearity. Dua variabel dapat dikatakan mempunya hubungan yang linear jika nilai signifikasi pada linearity > 0,05. Berikut adalah beberapa yang memperlihatkan hubungan antar variabel:

Uji Linearitas

\begin{tabular}{|l|c|}
\hline \multicolumn{1}{|c|}{\begin{tabular}{c}
\multicolumn{1}{|c|}{$\begin{array}{c}\text { Variabel } \\
\text { Penelitian }\end{array}$} \\
\hline $\begin{array}{l}\text { Komitmen Organisasional (Y1) dan Gaya } \\
\text { KepemimpinanTransformasional (X1) }\end{array}$
\end{tabular}} & $\begin{array}{c}\text { Signifikansi } \\
\text { Linearity }\end{array}$ \\
\hline Komitmen Organisasional (Y1) dan Lingkungan Kerja (X2) & 0,697 \\
\hline $\begin{array}{l}\text { Turnover Intention (Y2) dan Gaya } \\
\text { KepemimpinanTransformasional (X1) }\end{array}$ & 0,689 \\
\hline Turnover Intention (Y2) dan Lingkungan Kerja (X2) & 0,749 \\
\hline Turnover Intention (Y2) dan Komitmen Organisasi (Y1) & 0.238 \\
\hline
\end{tabular}

Sumber : Data olahan, 2020

\section{Uji Analisis Jalur, Uji Determinasi Total (R2), dan Uji Parsial (t).}

Analisis jalur merupakan teknis statistik untuk menguji hubungan kausal antara dua atau lebih variabel. Analisis jalur adalah bagian dari model regresi yang dapat digunakan untuk menganalisis hubungan sebab akibat antar satu variabel dengan variabel lainnya. Sistem hubungan sebab akibat tersebut menyangkut dua jenis variabel yaitu variabel bebas dan variabel terikat.

Model Summary Sub Struktur 1 Model Summary

\begin{tabular}{|l|r|r|r|r|}
\hline Model & R & R Square & Adjusted R Square & $\begin{array}{l}\text { Std. Error of } \\
\text { the } \\
\text { Estimate }\end{array}$ \\
\hline 1 &, $786^{\mathrm{a}}$ & 0,618 & 0,600 & 4.610 \\
\hline
\end{tabular}

a. Predictors: (Constant), Lingkungan (X2), Gaya Kepemimpinan Transformasional (X1)

b. Dependent Variable: Komitmen Organisasional (Y1) 
Pengaruh Kepemimpinan Transformasional dan Lingkungan Kerja terhadap Turnover Intention dengan Komitmen Organisasional sebagai Variabel Mediasi pada Karyawan

PT. Borneo Icon Properti

Dini Dwi Damayanti a

\section{Coefficients Sub Struktur}

1 Coefficientsa

\begin{tabular}{|c|c|c|c|c|c|}
\hline \multirow[t]{2}{*}{ Model } & \multicolumn{2}{|c|}{$\begin{array}{c}\text { Unstandardized } \\
\text { Coefficients }\end{array}$} & \multirow{2}{*}{$\begin{array}{c}\begin{array}{c}\text { Standardized } \\
\text { Coefficients }\end{array} \\
\text { Beta }\end{array}$} & \multirow[b]{2}{*}{$\mathrm{t}$} & \multirow[b]{2}{*}{ Sig. } \\
\hline & $\mathrm{B}$ & Std. Error & & & \\
\hline 1 (Constant) & -4.516 & 5.433 & & -.831 & .410 \\
\hline Kepemimpinan & .340 & .138 & .379 & 2.463 & .018 \\
\hline Transoformasional & & & & & \\
\hline Lingkungan Kerja & .485 & .165 & .453 & 2.949 & .005 \\
\hline
\end{tabular}

a. Dependent Variable: Komitmen Organisasional

\section{Model Summary Sub Struktur 2}

Model Summaryb

\begin{tabular}{|l|c|r|r|r|}
\hline Model & $\mathrm{R}$ & R Square & $\begin{array}{c}\text { Adjusted } \\
\text { RSquare }\end{array}$ & $\begin{array}{c}\text { Std. Error of } \\
\text { the } \\
\text { Estimate }\end{array}$ \\
\hline 1 & $.142^{\mathrm{a}}$ & .020 & -.052 & 8.495 \\
\hline
\end{tabular}

a. Predictors: (Constant), Komitmen Organisasional(Y1), Gaya Kepemimpinan Transformasional(X1), Lingkungan Kerja (X2)

b. Dependent Variable: Turnover Intention (Y2)

Coefficients Sub Struktur 2

Coefficientsa

\begin{tabular}{|c|c|c|c|c|c|}
\hline \multirow[t]{2}{*}{ Model } & \multicolumn{2}{|c|}{ Unstandardized Coefficients } & \multirow{2}{*}{$\begin{array}{c}\text { Standardized } \\
\text { Coefficients } \\
\text { Beta }\end{array}$} & \multirow[b]{2}{*}{$\mathrm{t}$} & \multirow[b]{2}{*}{ Sig. } \\
\hline & B & Std. Error & & & \\
\hline (Constant) & 21.269 & 10.093 & & 2.107 & .041 \\
\hline Kepemimpinan & .085 & .273 & .083 & .311 & .757 \\
\hline \multicolumn{6}{|l|}{ Transformasional } \\
\hline Lingkungan Kerja & -.060 & .333 & -.050 & -.181 & .857 \\
\hline Komitmen & -.178 & .284 & -.157 & -.627 & .534 \\
\hline Organisasional & & & & & \\
\hline
\end{tabular}

a. Dependent Variable: Turnover Intention

\section{Sobel Test}

Uji sobel ini digunakan untuk mengetahui pengaruh variabel mediasi yaitu komimen organisasional pengaruh mediasi yang ditunjukan oleh perkalian koefisien (ab) perlu diuji dengan Sobel test sebagai berikut: 
Tabel

Hasil Data Olahan Untuk Perhitungan Sobel Test

\begin{tabular}{|c|c|c|c|}
\hline $\begin{array}{c}\text { Variabe } \\
\mathbf{l}\end{array}$ & $\begin{array}{c}\text { Standardize } \\
\mathbf{d} \\
\text { Coefficient }\end{array}$ & $\begin{array}{l}\text { Unstandardize } \\
\mathbf{d C o e f f i c i e n t} \\
(\boldsymbol{\beta})\end{array}$ & $\begin{array}{c}\text { Std } \\
\text { error }\end{array}$ \\
\hline $\mathrm{X} 1$-> Y & 0.379 & 0.340 & 0.138 \\
\hline $\mathrm{X} 2->\mathrm{Y}$ & 0.453 & 0.485 & 0.165 \\
\hline $\mathrm{X} 1->\mathrm{Z}$ & 0.083 & 0.085 & 0.273 \\
\hline $\mathrm{X} 2->\mathrm{Z}$ & -0.050 & -0.060 & 0.333 \\
\hline $\mathrm{Y}->\mathrm{Z}$ & -0.157 & -0.178 & 0.284 \\
\hline
\end{tabular}

(Sumber: data diolah, 2020)

\section{Variabel kepemimpinan transformasional terhadap turnover intention} melalui komitmen organisasional

t hitung $<\mathrm{t}$ tabel yaitu $-7,749<1,679$ yang berarti koefisien mediasi tidak signifikan, artinya tidak ada pengaruh mediasi antara kepemimpinan transformasional (X1) terhadap turnover intention (Z) melalui komitmen organisasional (Y).

\section{Variabel lingkungan kerja terhadap turnover intention melalui komitmen} organisasional

t hitung $<$ t tabel yaitu $-11,381<1,679$ yang berarti koefisien mediasi tidak signifikan, artinya tidak ada pengaruh mediasi antara lingkungan kerja (X2) terhadap turnover intention (Z) melalui komitmen organisasional (Y).

\section{Pengaruh Gaya Kepemimpinan Transformasional terhadap Komitmen Organisasional}

Mengacu pada output hasil regresi model 1 (sub struktur 1) pada tabel 4.22 model summary nilai $\mathrm{R}$ square sebesar 0.618 atau sebesar $61.8 \%$ pengaruh variabel gaya kepemimpinan transformasional dan Tabel coefficients sub struktur 1 dapat diketahui bahwa nilai signifikasi dari variabel gaya kepemimpinan transformasional sebesar 0,018<0.05 sehingga dapat disimpulkan bahwa berpengaruh secara positif dan signifikan.

Pengaruh Lingkungan Kerja terhadap Komitmen Organisasional 
Pengaruh Kepemimpinan Transformasional dan Lingkungan Kerja terhadap Turnover Intention dengan Komitmen Organisasional sebagai Variabel Mediasi pada Karyawan PT. Borneo Icon Properti Dini Dwi Damayanti a

Mengacu pada output hasil regresi model 1 (sub struktur 1) pada tabel 4.22 model summary nilai $r$ square sebesar 0.618 atau sebesar $61,8 \%$ lingkungan kerja terhadap komitmen organisasional. Tabel Coefficients Sub Struktur 1 dapat diketahui bahwa nilai signifikasi dari variabel lingkungaan kerja sebesar $0,005<0.05$ sehingga dapat disimpulkan bahwa berpengaruh secara positif dan signifikan.

\section{Pengaruh Gaya Kepemimpinan Transformasional terhadap Turnover Intention}

Mengacu pada output hasil Regresi Model 2 (Sub Struktur 2) pada Tabel 4.24 Model summary nilai R square sebesar 0.298 atau sebesar $29.8 \%$ pengaruh variabel gaya kepemipinan transformasional terhadap turnover intention. Tabel coefficients sub struktur 2 dapat diketahui bahwa nilai signifikasi dari variabel gaya kepemimpinan transformasional sebesar $0.757>0.05$ sehingga dapat disimpulkan bahwa berpengaruh negatif dan tidak signifikan terhadap turnover intention.

\section{Pengaruh Lingkungan Kerja terhadap Turnover Intention}

Mengacu pada output hasil Regresi Model 2 (Sub Struktur 2) pada Tabel 4.24 Model summary nilai $\mathrm{R}$ square sebesar 0.298 atau sebesar $29.8 \%$ pengaruh variabel lingkungan kerja terhadap turnover intention. Variabel lingkungan kerja sebesar $0.857>0.05$ dengan beta $-0,060$ dapat disimpulkan berpengaruh negatif dan tidak signifikan terhadap turnover intention.

\section{Pengaruh Komitmen Organisasional terhadap Turnover Intention}

Mengacu pada output hasil Regresi Model 2 (Sub Struktur 2) pada Tabel 4.24 Model summary nilai R square sebesar 0.298 atau sebesar $29.8 \%$ pengaruh variabel lingkungan kerja terhadap turnover intention. Tabel 4.25 coefficients sub struktur 2 dapat diketahui bahwa nilai signifikasi dari variabel Komitmen Organisasional sebesar $0.534>0.05$ dengan beta - 0,178 sehingga dapat disimpulkan berpengaruh negatif dan tidak signifikan terhadap turnover intention.

\section{Pengaruh Kepemimpinan Transformasional terhadap Turnover Intention melalui Komitmen Organisasional}

Mengacu pada output hasil Regresi Model 2 (Sub Struktur 2) pada Tabel 4.24 Model summary nilai R square sebesar 0.298 atau sebesar $29.8 \%$ pengaruh variabel gaya kepemipinan transformasional terhadap turnover intention melalui komitmen organisasional pada. Tabel coefficients sub struktur 2 dapat diketahui bahwa nilai signifikasi dari variabel gaya kepemimpinan transformasional sebesar $0.757>0.05$ sehingga dapat disimpulkan bahwa berpengaruh negatif dan tidak signifikan terhadap turnover intention melalui komitmen organisasional.

\section{Pengaruh Lingkungan Kerja terhadap Turnover Intention melalui Komitmen Organisasional}

Mengacu pada output hasil Regresi Model 2 (Sub Struktur 2) pada Tabel 4.24 Model summary nilai $\mathrm{R}$ square sebesar 0.298 atau sebesar $29.8 \%$ pengaruh variabel lingkungan kerja terhadap turnover intention melalui komitmen organisasional.. Variabel lingkungan kerja sebesar $0.867>0.05$ dengan beta -0,060 dapat disimpulkan berpengaruh negatif dan tidak signifikan terhadap turnover intention. 
Pengaruh Kepemimpinan Transformasional dan Lingkungan Kerja terhadap Turnover Intention dengan Komitmen Organisasional sebagai Variabel Mediasi pada Karyawan

PT. Borneo Icon Properti

Dini Dwi Damayanti a

\section{KESIMPULAN DAN SARAN \\ Kesimpulan}

Penelitian ini bertujuan untuk menguji pengaruh kepemimpinan transformasional dan lingkungan kerja terhadap turnover intention dengan komitmen organisasional sebagai variabel mediasi pada karyawan PT. Borneo Icon Properti. Dari pembahasan yang telah diuraikan, maka dapat ditarik kesimpulan sebagai berikut:

1. Variabel gaya kepemimpinan transformasional berpengaruh secara positif dan signifikan terhadap komitmen organisasional pada karyawan PT. Borneo Icon Properti.

2. Variabel lingkungan kerja berpengaruh secara positif dan signifikan terhadap komitmen organisasional pada karyawan PT. Borneo Icon Properti.

3. Variabel gaya pemimpinan transformasional berpengaruh negatif dan tidak signifikan terhadap turnover intention pada karyawan PT. Borneo Icon Properti.

4. Variabel lingkungan kerja berpengaruh negatif dan tidak signifikan terhadap turnover intention pada karyawan PT. Borneo Icon Properti.

5. Variabel komitmen organisasional berpengaruh negatif dan tidak signifikan terhadap turnover intention pada karyawan PT. Borneo Icon Properti.

6. Secara simultan (keseluruhan) kepemimpinan transformasional melalui komitmen organisasional tidak berpengaruh secara signifikan terhadap turnover intention pada karyawan PT. Borneo Icon Properti.

7. Secara simultan (keseluruhan) lingkungan kerja melalui komitmen organisasional tidak berpengaruh secara signifikan terhadap turnover intention pada karyawan PT. Borneo Icon Properti.

\section{Saran}

Berdasarkan hasil penelitian dan kesimpulan yang telah penulis uraikan, maka saran yang dapat direkomendasikan adalah:

1. Pada variabel kepemimpinan transformasional, dan lingkungan kerja tidak berpengaruh terhadap turnover intention maka perlu bagi perusahaan untuk meningkatkan komitmen karyawan agar dapat bertahan untuk bekerja diperusahaan dengan baik serta memperhatikan variabel-variabel lain yang dapat meningkatkan komitmen karyawan sehingga pada akhirnya dapat meminimalisir naiknya angka turnover di perusahaan khususnya di PT. Borneo Icon Properti.

2. Bagi penelitian selanjutnya disarankan untuk menambah atau menggunakan variabel-variabel bebas lainnya selain gaya kepemimpinan transformasional dan lingkungan kerja maupun variabel komitmen organisasional yang dapat mempengaruhi turnover intention sehingga pada penelitian selanjutnya dapat lebih menyempurnakan hasil penelitian ini.

\section{Daftar Pustaka}


Pengaruh Kepemimpinan Transformasional dan Lingkungan Kerja terhadap Turnover Intention dengan Komitmen Organisasional sebagai Variabel Mediasi pada Karyawan PT. Borneo Icon Properti Dini Dwi Damayanti a

Ajzen, I. 1980. From Intentions to Actions: A Theory pf Planned Behavior". In J. Kuhl and J. Beckman (Eds.), Action-Control: From Cognition to Behavior (hal. 1139). Heidelberg: Springer.

Allen, N.J. \& Meyer, J.P. 1990. The Measurement and Antecedents of Affective,Continuance \& Normative Commitment to the Organization. Journal of Occupational Psychology, 63, 1-18

Çınar, 0. 2015. The relationships between mobbing, organizational citizenship behavior and turnover intention: A survey study in Erzurum/Turkey. Journal of Global Strategic Management, 9(1), 87-98.

Clinebell, S. 2013. The impact of leadership style on employee organization commitment. Journal of Service Science.

Danish, R. Q., Ramzan, S., \& Ahmad, F. (2013). Effect of perceived organizational support and work environment on organizational commitment: Mediating role of self- monitoring. Advances in Economics and Business, 1(4), 312-317.

Dwivedi, S. 2015. Turnover intentions: Scale construction \& validation. Indian Journal of Industrial Relations, 50, 452-469.

Faldetta,G., Fasone,V., Provenzano, C. 2013. Turnover in the Hospitality Industry: Can Reciprocity Solve the Problem?. Journal of Revista de Turismo y Patrimonio Cultural Vol.11 No.4 page 583-595 Faculty of Economics and Law Kore University of Enna Italy.

Griffeth, R.W., P.W. Hom, dan S. Gaertner. 2000. A Meta-Analysis of Antecedents and Correlates of Employee Turnover: Update, Moderator Tests, and Research Implications for the Next Millenium. Journal of Management. 26(3): 463488.

McGuire, David and McLaren, Lauren. 2009. The impact of physical environment on employee commitment in call centres - The mediating role of employee wellbeing. Team Performance Management. Vol.15No.1/2, pp.35-48.

Rafitas, A. B. 2005. Kiat Sukses Bisnis Broker Properti. Bumi Aksara, Jakarta

Rego, A \& Cunha, M.P. 2008. Workplace Spirituality and Organizational Commitment : An Empirical Study. Journal of Organizational Change Management 21(1):53-75

Ridlo, I.A. 2012. Turnover Karyawan-Kajian Literatur. Surabaya : PH Movement Publication

Robbins, S. \& Timothy A,J. 2010. Perilaku Organisasi. Jakarta: Salemba Empat. Edisi ke-16. Satwari, T., Musadieq, M.A., \& Afrianty, T.W. 2016. Pengaruh Komitmen Organisasional 
Pengaruh Kepemimpinan Transformasional dan Lingkungan Kerja terhadap Turnover Intention dengan Komitmen Organisasional sebagai Variabel Mediasi pada Karyawan

PT. Borneo Icon Properti

Dini Dwi Damayanti a

Terhadap Turnover Intention. Jurnal Administrasi Bisnis (JAB) Vol. 40 No. 2 Sedarmayanti. 2009. Manajemen SDM cetakan 1. Bandung: PT. Refika Aditama.

Sugiyono. 2012. Memahami Penelitian Kualitatif. Bandung: Alfabeta.

shaWei Su H, Li-Tze L, Chiang-Ku F. 2014 Turnover Determinants of New Employees in International Hotels. Journal of Service Science and Management 4: 158-164. 